Send your letters to the Editor,

British Dental Journal,

64 Wimpole Street

London

W1G 8YS

Email bdj@bda.org

Priority will be given to letters less than 500 words long.

Authors must sign the letter, which

may be edited for reasons of space.

\section{FABRICATED ILLNESS}

Sir, I was interested in the article by McDonnell and Mackie (BDJ 2008; 205: 593-595) about a suspected case of child abuse. A 3-year-old child had been referred because of an allegation made by a mother that her husband had harmed their daughter by pushing a metal nail into the girl's gum. The 'nail' turned out to be a flat metallic disc lying on the gingival surface, perhaps a sequin, and was therefore not a nail. The accusation made by the woman, who was separating from her husband at the time the allegation was made, was therefore unfounded. The authors conclude that 'there was no abuse'.

I wonder if the authors had considered the possibility of fabricated illness. The cardinal feature of fabricated illness is the production or feigning of symptoms in another person. The victim of fabricated illness is often a child. The individual who has fabricated illness gains secondary benefit in some way, for example by getting attention, or by establishing close links with healthcare personnel. The Diagnostic and statistical manual of mental disorders (DSM) ${ }^{1}$ is the standard classification of mental disorders used by mental health professionals in the United States, and it is widely used in the UK. Fabricated illness is not listed separately in it, but can be classified as a factitious disorder not otherwise specified. Fabricated illness can be perpetrated by parents, carers or healthcare professionals. Fabricated illness is regarded as a form of child abuse.

Since the metallic object on the surface of the patient's gum was not a nail pushed into the gum, by the father, at least two possible scenarios exist. The first is that the mother was genuinely mistaken, and believed the father had deliberately harmed his daughter (even if he had not) and that she had acted appropriately in the circumstances. Another scenario is that she deliberately placed the metallic disc on the gum herself, with the intention of implicating the father during the separation process. The first scenario indicates how badly the relationship with her daughter's father has deteriorated, but also suggests that she may need psychological support. The second scenario is suggestive of fabricated illness, itself a form of child abuse.

Although dentists can detect child abuse and non-accidental injuries, often such diagnoses are notoriously difficult, and often, regrettably, retrospective. The diagnosis is often the result of a jigsaw of small segments of clinical contacts with different healthcare professionals over a period of time being pieced together.

The authors are to be congratulated on following procedures on child protection, and are correct in their assertion that the dental team has a vital role in child protection. Perhaps fabricated illness ought to have been considered in this particular case, and it is always important to inform the child's GP that there had been suspicions of abuse, or an unusual clinical contact.

A. Ali

Blackburn

1. American Psychiatric Association. Diagnostic and statistical manual of mental disorders, 4th ed, text revision (DSM-IV-TR).

DOI: 10.1038/sj.bdj.2009.173

\section{ACRONYMS}

Sir, I am sure that we are not short of printing ink but what is "the academic lead for MSF in clinical assessment at
NCAS'? (Foot of page 53, BDJ Volume 206 issue 2.)

\section{S. Bazlington}

Essex

Ed's note: We apologise for the oversight: MSF is Multi-Source Feedback and NCAS is the National Clinical Assessment Service.

DOI: 10.1038/sj.bdj.2009.174

\section{CANINE TONGUE TRAUMA}

Sir, we thought that your readers would appreciate this new method of tongue piercing removal; it is not one to be recommended on a regular basis, however!

A 32-year-old man presented to the maxillofacial on-call service via the accident and emergency department complaining that his tongue ring had been removed by his Greyhound dog. Whilst he was playing with his dog, the dog managed to hook its lower canine tooth around the owner's tongue ring; once engaged, the dog got such a fright that it forcibly retracted and thereby pulled the ring through the midline of the tongue. Medically, the man was found to be fit and well. On examination he was found to have a through and through midline tongue laceration causing a forked tongue appearance. There was both a raw area of granulation tissue and an epithelialised tract suggestive of a recently traumatised but long-standing piercing (see Fig. 1); in addition, there was a small mucosal message!

Under a day case general anaesthetic, the patient had excision of the wound edges and primary closure of the wound with resorbable sutures (Figs 2 and 3). He made an uneventful recovery. The dog declined to have his photograph taken! 


\section{LETTERS}

There can be several, even life threatening, complications to tongue piercings and their subsequent removal, ${ }^{1}$ but removal by canine guidance is not a commonly reported method.

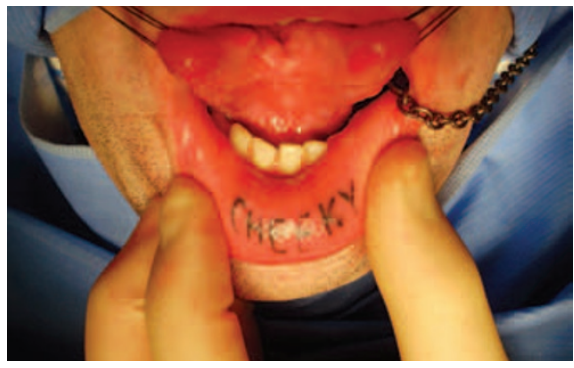

Fig. 1 Bifid/forked tongue injury

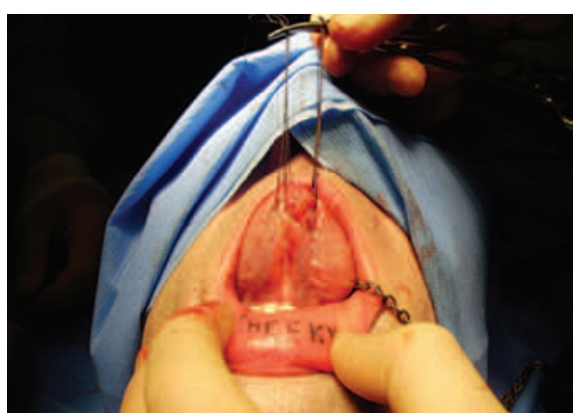

Fig. 2 Repaired ventral surface of tongue

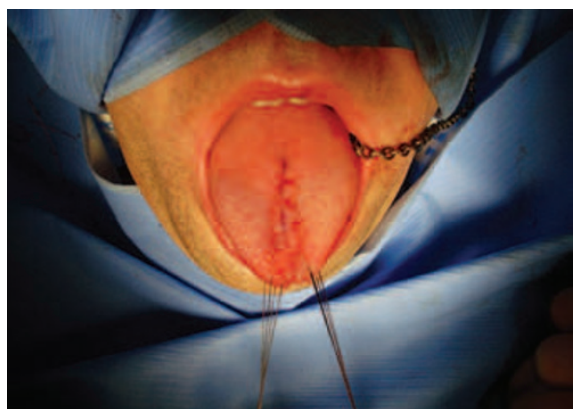

Fig. 3 Repaired dorsum of tongue

P. Gill, R. M. Graham, E. F. Thomson, Manchester

1. Garcia-Pola M J, Garcia-Martin J M, VarelaCentelles P, Bilbao-Alonso A et al. Oral and facial piercing: associated complications and clinical repercussion. Quintessence Int 2008; 39: 51-59.

DOI: 10.1038/sj.bdj.2009.175

\section{CONTRASTING FINDINGS}

Sir, in the recent letter Bisphenol alert (BDJ 2008; 205: 583), the sentence 'The overall conclusion is that there is little to worry about...' appeared. This contrasts with findings of other workers in the field. The topic of human exposure to compounds which have potential oestrogenic influence has aroused interest from different branches of medicine. Adult or mature mammalian subjects have been used in experimental models in the past. However, findings change and questions are raised when the immature or growing mammalian subject is used within the experimental model. Work is now being directed towards specific time frames in which compounds may exert irreversible influence on developmental pathways on the growing embryo. Work done by Vom Saal, and others, has contributed to this debate. He found $2 \mathrm{ng} / \mathrm{g}$ body weight ( $2 \mathrm{ppb}$ ) of bisphenol $\mathrm{A}$, fed to mice between 11 to 17 days gestation, produced a permanent change in the developmental pathways of specific organs. ${ }^{1}$ This work has been independently verified by others.

It is recognised that the contents of resin based restorative materials used in dental practice cannot be solely responsible for the total body burden a patient may be exposed to. However, the likelihood exists that they may contribute towards overall exposure of the patient. In order for the dental community to contribute meaningfully to wider scientific discussion in this area, further research would be welcome.

F. Moran

Gloucester

1. Vom Saal F, Cooke P et al. A physiologically based approach to the study of bisphenol $A$ and other estrogenic chemicals on the size of reproductive organs, daily sperm production, and behavior. Toxicol Ind Health 1998; 14: 239-260.

DOI: $10.1038 /$ sj.bdj.2009.176

\section{INTUITIVE RECORDING}

Sir, I would like to share with your readers a suggestion for a simple method to record the preoperative evaluation of the impacted third molar. It combines Pell-Gregory's ramus classification and Pell-Gregory's occlusal classification with Winter's classification in a table. It is intuitive, which would be helpful in communication with patients, and it can be used both in clinical judgement and statistical research.

First we locate Pell-Gregory's ramus classification (marked I II III) and PellGregory`s occlusal classification (marked A B C) in a table. For different sides of a dentition, the orientations are opposite (Figs 1-2). The horizontal tables indicate Pell-Gregory's ramus classification and the vertical tables indicate Pell-Gregory occlusal classification. Background images show the position of each blank in the dentition; teeth in the images are C7 or D7.

Then we transform Winter's classification into arrows by marking the vertical impaction as $\uparrow$, the mesioangular impaction as $\nwarrow$ or $\nearrow$, the distoangular impaction as $\$ or $\lambda$, the buccoangular impaction as $\oplus$, the linguoangular impaction $\odot$, the horizontal impaction as $\leftarrow$ or $\rightarrow$ and the inverted impaction as $\downarrow$.

For example, if a C8 is impacted and its preoperative evaluation is class II, middle-position, mesioangular impaction, it could be recorded as in Figure 3. Similarly, if a D8 is impacted and its preoperative evaluation is Class III, lowposition, buccoangular impaction, it could be recorded as in Figure 4.

The table also has another benefit in that it can be used to evaluate impacted teeth with direct scores. If we give value to blanks (Fig. 5) and arrows to assess the difficulty of extraction M3, we can get the total score of each impacted tooth conveniently. This could be of benefit both to clinical judgement and statistical research.

If the vertical impaction $(\uparrow)$ is worth 1 , the mesioangular impaction and the distoangular impaction ( $\nwarrow$ or $\nearrow$ ) are both worth 2, the buccoangular impaction $(\oplus)$ is worth 3 , the linguoangular impaction $(\odot)$ is worth 4 , the horizontal impaction $(\leftarrow$ or $\rightarrow$ ) is worth 5 and the inverted impaction $(\downarrow)$ is worth 6 , then Fig. 3 is worth: $2(\mathrm{II})+2(\mathrm{~b})+2(\ltimes)=6$ and Fig. 4 is worth: $3(\mathrm{III})+3(\mathrm{C})+3(\oplus)=9$.
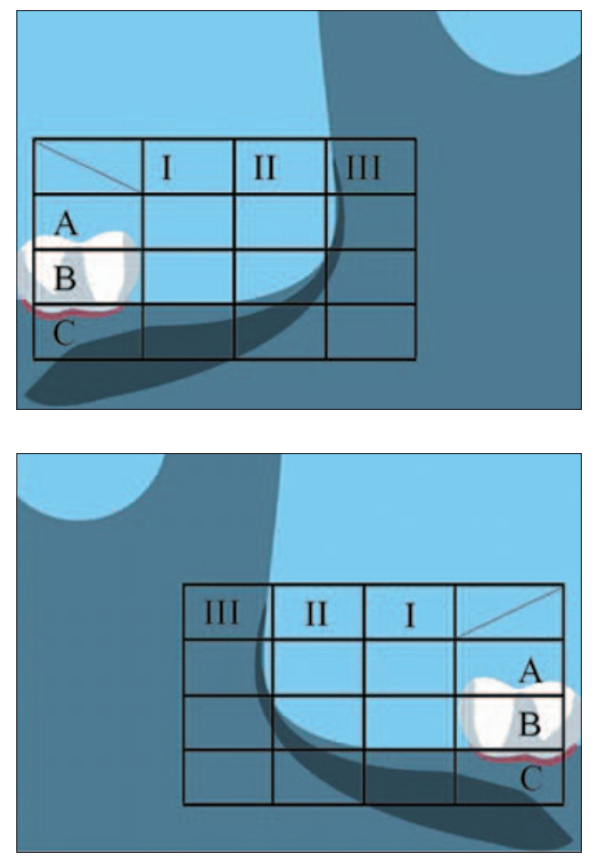

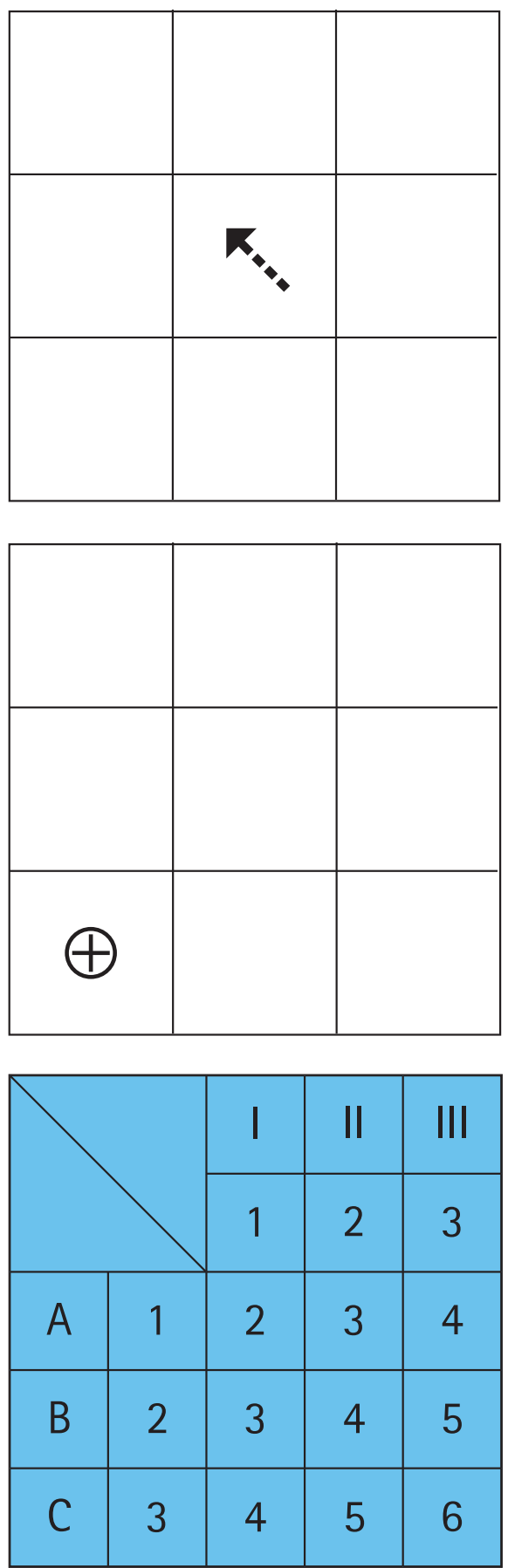

Figs 1-5 A simple method to record the preoperative evaluation of the impacted third molar

Y. Yao

Chengdu, China

DOI: 10.1038/sj.bdj.2009.177

\section{A HUNGER TO BUY}

Sir, given all the doom and gloom that is constantly being reported about the general economy I thought I would share my view on the business of dentistry - it is alive and kicking!

We have been valuing and selling dental practices for longer than most dentists can remember and 2009 has started like most years. There is a real hunger to buy dental practices across the board, from young recently qualified dentists through to the Dental Body Corporates. The value of dental practices are holding up, which perhaps isn't surprising given the demand and good profitability we see in most practices.

Whilst there is no doubt 2009 will present a range of challenges, I believe that dentistry has the opportunity to rise to these challenges and continue to perform well.

A. Acton

Director, Frank Taylor Associates DOI: 10.1038/sj.bdj.2009.178

\section{UNSUITABLE PRESCRIBING}

Sir, I was somewhat surprised to read the letter A single dose (BDJ 2008; 205: $525)$, in which the author routinely prescribed a single dose of metronidazole $200 \mathrm{mg}$ post-operatively for the prevention of dry socket.

A recent literature review on dry socket by Noroozi et al. ${ }^{1}$ states the incidence of dry socket for a young, healthy and non-smoking young male to carry a 1-4\% risk. Risk factors such as traumatic extractions, age, gender and mandibular teeth were also highlighted. Noroozi identified that antimicrobials can help to prevent dry socket, of which metronidazole was shown to have the greatest effect, but only if taken pre-operatively. The use of systemic antimicrobials was also only recommended for the immunocompromised patient.

NICE guidelines published October $2008^{2}$ for the prevention of post surgical infection state that antibiotic prophylaxis should not be used routinely for clean non-prosthetic surgery. If antibiotics were indicated, then a single dose preoperatively, or intravenously at the time of starting the procedure, should be considered. The use of post-operative antibiotics is only indicated when surgical site infection is suspected.

In a time where we are seeing incidences of antimicrobial drug resistance, prudent prescribing of antimicrobials by healthcare professionals is essential. I therefore feel that this particular prescribing could only be regarded as not only ineffective, but inappropriate.

P. T. Glen, Liverpool
1. Noroozi A R, Philbert R F. Modern concepts in understanding and management of the 'dry socket' syndrome: comprehensive review of the literature. Oral Surg Oral Med Oral Pathol Oral Radiol Endod 2008; in press.

2. NICE Clinical Guideline 74 'Surgical Site Infection - Prevention and treatment of surgical site infection.' October 2008.

DOI: $10.1038 /$ sj.bdj.2009.179

\section{NOT AN AUTHORITY}

Sir, I heartily agree with E. Shawkat (Wikipedia use, BDJ 2009; 206: 117) - Wikipedia should not be used for anything but a general interest tool. It is certainly not to be cited as an authority as anyone may state anything on its pages that they believe is true, regardless of evidence.

For example, if you look under 'tooth eruption', it is stated that periodontal ligament cross linking and contraction causes the tooth to erupt. This was suggested as a possible factor in tooth eruption some 30 years ago, but has long since been discredited. It is now widely accepted that tooth eruption is effected through vascular changes whereas to date, there is no mention of this on Wikipedia (unless Professor Moxham has time to update the site before this letter is published?)

R. Kitchen, Bristol DOI: 10.1038/sj.bdj.2009.180

\section{A REMARKABLE COINCIDENCE}

Sir, the dilemma you expressed in the December 2008 (issue 11) British Dental Journal (BDJ 2008; 205: 598-599) regarding the study on a possible relationship between dental and mental health led to a remarkable coincidence. The following day, after reading your note, I was researching a local paper (The Times of Malta, July 1936) on a different topic when I came across a half page article on dental and medical health. This was obviously an agency news item (probably Reuters) which dealt with a research study carried out at Birmingham University. It showed a correlation between mental and oral health and dental treatment (ie extractions) gave positive results. There was no mention of the persons carrying out the study nor the department concerned. I am afraid I cannot verify whether the recent study referred to the 1936 one but I felt it may be of interest to you.

\section{G. E. Camilleri}

Malta

DOI: 10.1038/sj.bdj.2009.181 